\title{
College prizes
}

\section{Janssen Prize for Computer Applications in Psychiatry}

The Computers in Psychiatry Special Interest Group of the Royal College of Psychiatrists wishes to encourage the involvement of trainees in psychiatry in the development of computer applications in the specialty.

A Prize of $£ 500$ will be awarded in 1992 for an essay of between 3,000 and 5,000 words, describing either the adaptation of a particular package in relation to psychiatry or the development of a computer programme which has applications in psychiatry. The essay may be accompanied by the relevant software. The Prize may only be awarded to Members or Inceptors of the College below the rank of consultant or equivalent at the time the entry is submitted.

Entries will be judged by Professor R. McClelland (Sub-Dean) and assessors appointed by the Executive Committee of the Computers in Psychiatry Special Interest Group. The successful candidate may be invited to present a paper at the Group's Annual Scientific Meeting. No Prize will be awarded if a sufficient standard is not reached.

Entries should be submitted to the Secretary of the Group, Dr Martin Briscoe, at Wonford House Hospital, Dryden Road, Wonford, Exeter, Devon EX2 5AF, no later than 30 April 1992.

\section{Philip Davis Prize in Old Age Psychiatry}

The Prize was established in 1991 and derives from the estate of the late Dr Philip R. H. Davis, a Member of the College for over $\mathbf{4 0}$ years and, at the time of his death, consultant psychiatrist in the Reading Hospitals Group.

The Philip Davis Prize (value $£ 300$ ) is awarded annually under the auspices of the Royal College of Psychiatrists for an essay of between 4,000 and 6,000 words on a broadly-based clinical topic relating to the care of the elderly mentally ill. The Prize may only be awarded to Members or Inceptors of the College below the rank of consultant psychiatrist or the equivalent at the time the essay is submitted. Each application should be accompanied by a concise curriculum vitae. In line with Dr Davis' wishes, attention will be given by the examiners to the literacy of the submissions.

Recipients of the Prize may be invited to present a report at a Scientific Meeting of the Specialist Section for Old Age Psychiatry.

The examiners for the Prize will be the Dean and two assessors appointed by the Old Age Psychiatry Section. No Prize will be awarded if a sufficient standard is not reached.

Entries for the Prize should be submitted to the Dean by 30 April 1992.

\section{Obituary}

\section{Editor: Henry R. Rollin}

\section{Gerald Bernard Simon, formerly Professor of Mental Handicap, University of Birmingham}

Professor Gerry Simon, founder and first director of the British Institute of Mental Handicap and director of the National Development Team, died on 14 July 1991 at the age of 71.

In a professional life truncated by war service, Gerry Simon established in a remarkably short time a leadership role in the treatment and care of people with a learning and sensory disability. At the time he started, this cinderella of professions was undergoing a particularly turbulent phase, following a series of damaging inquiries starting in the mid 1960 s into the conditions in mental handicap and mental illness hospitals. It was through his force of character, his vision and an ability to mobilise the energies of colleagues that proposals for change were implemented through the work of the National Development Team and that the British Institute, a nationwide multiprofessional organisation, was established. He also played a major part with other university departments in regaining academic respectability for the profession.

Gerry Simon was born in South India where his family was in business. After leaving school in India, 
he attended the University of Madras, but his studies were interrupted by the war. He joined the army and served in the infantry in South East Asia Command including service in the Wiltshire Regiment. He was involved in undercover work behind enemy lines in Burma, was captured by the Japanese and escaped by walking out of Burma. As a result he contracted pulmonary tuberculosis which was to cause him problems later in life.

During the latter part of the war he married his wife, Marjorie, who was serving in the WRNS in Columbo and on his return to England received further sanatorium treatment. He had always wanted to be a doctor and he eventually obtained an ex. service grant to read medicine at Bristol University graduating $\mathrm{MB}, \mathrm{ChB}$ in 1957 . Following house appointments in the west country he decided to take up psychiatry. It was, he said, the only way he could support his young family at the time and maintain personal contact with people which was the primary objective of his professional life. He trained in the Oxford region, notably at the Smith Hospital in Henley, a pioneer unit for the treatment of autistic children, and it was while he was there that he published his first papers on the growth and early development of children with autism. This and his final move to the West Midlands where he took up a consultant post at the Lea and Lea Castle Hospitals in Bromsgrove and Kidderminster led to his pioneering lifetime interest in the learning difficulties of sensorily impaired children, particularly those with severe visual handicap. This may have also been influenced by his own loss of an eye earlier in life.

He set up units at Lea and Lea Castle Hospitals for the diagnosis, assessment and treatment of children with multiple handicaps which formed a basis for further research and led to the scheme of assessment and treatment Next Steps in the Ladder which remains, after several editions, as a refreshingly simple and straightforward manual of guidance for parents and professionals. He served as consultant to the RNIB at Condover Hall in Shropshire and in Birmingham was involved in the inauguration of the Rubella Deaf Blind Association later to be known as SENSE. He was also president of the West Midlands Autistic Society.

Mrs Barbara Castle, in response to the slow progress over the implementation of the recommendations of the 1971 White Paper Better Services for the Mentally Handicapped set up the National Development Group under the chairmanship of Professor Peter Medlar and Gerry Simon was invited to serve as Vice Chairman and the first director of the National Development Team who, over the next fourteen years, issued a number of pamphlets, notably on the provision of community mental handicap teams, community units and day services. With a panel of over 70 professionals and parents the team carried out visits, inspection and gave advice at the invitation of local health and social services throughout the country. Inevitably, there was criticism about the team's report but this opening up of services to public view led to a firm systematic basis for the provision of community care in this country.

Gerry Simon's most lasting memorial will be the establishment in 1971 of the British Institute of Mental Handicap (BIMH). He again pressed into service an enthusiastic group of volunteers representing all disciplines involved in the care of people with a learning disability. The clear focus of the Institute as multidisciplinary training and objective research rather than acting as a mere pressure group, has done much to offset the professional fragmentation which threatened the services 20 years ago. BIMH has now become the major multiprofessional organisation in the field with a divisional network covering the whole of the British Isles, an achievement which owes much to his vision and organisational skills.

Gerry Simon was appointed to a personal chair at Birmingham University in 1984 in recognition of his skills as an undergraduate and postgraduate teacher: he had a particular gift for inspiring interest in an often neglected field of medical education. He had an ability to cut through official apathy to secure the best care for his patients and their families and this is epitomised in his book the Modern Management of Mental Handicap published in 1980.

Following his retirement in 1986 from the University he continued to serve as consultant at Lea Castle Hospital and to the Rugby Health Authority until shortly before his death. A devoted family man of wide interest, Professor Simon is survived by his wife and three children.

J. A. Corbett 